\title{
ARE YOUR PATIENTS EATING WELL? PROMOTING NUTRITION AND HEALTH
}

\section{Sue Lupson, Manager, Nutrition \& Dietetic Service Lancaster Priority Services Trust}

It is now well accepted that what we eat affects our heath in the short and long term.

The Health of the Nation ${ }^{(1)}$ and the COMA report ${ }^{(2)}$ make it clear that diet can contribute to the aetiology of many conditions, including coronary heart disease (CHD), stroke, obesity, osteoporosis, dental decay, iron deficiency anaemia and spina bifida. Doll ${ }^{(3)}$ has estimated that $10-70 \%$ of all cancer deaths are attributable to diet.

Despite the logical belief that nutrition influences health, many people are not eating more healthily since the publication of reports such as The Health of the Nation ${ }^{(1)}$. In fact the prevalence of obesity is rising. In 1991, $12.7 \%$ of men and $15 \%$ of women were obese (BMI>30). By 1994 these proportions had risen to $13.2 \%$ and $16 \%$ respectively and more than $50 \%$ of the adult population could now be said to be overweight $(\mathrm{BMI}>25)$. The percentages are higher in the lower social classes ${ }^{(4)}$.

So, are we to give up? Is it worth the effort of trying to encourage and enable people to eat more healthily? I would say that it is, and that our chances of influencing peoples' eating habits are increased if we consider the following:

- ensuring that the advice we give is up-to-date, consistent, understandable and relevant to patients' needs

- acknowledging that changing lifestyle, including $\operatorname{diet}^{(5)}$ is difficult and takes time and persistent effort and encouragement

- remembering that there are many socio-economic factors which make a healthy diet less accessible to certain groups of people ${ }^{6}$.

\section{CURRENT DIETARY GUIDELINES ${ }^{(7,8)}$}

Fat is made of varying proportions of different substances, including fatty acids. The main groups of fatty acids are saturates, monounsaturates and polyunsaturates. Two types of polyunsaturates cannot be made by the body, and are called essential fatty acids. These essential fatty acids form the basis of two families of fatty acids, known as n-6 and n-3.

The usual shape of molecules of naturally-occurring unsaturated fatty acids is called 'cis'. Some are in another form which more closely resembles that of saturates, and these are called 'trans' fatty acids. Trans fatty acids can occur naturally, or can be formed during some types of food processing.

\section{Saturates}

Sources in the diet include milk and dairy products, meat and

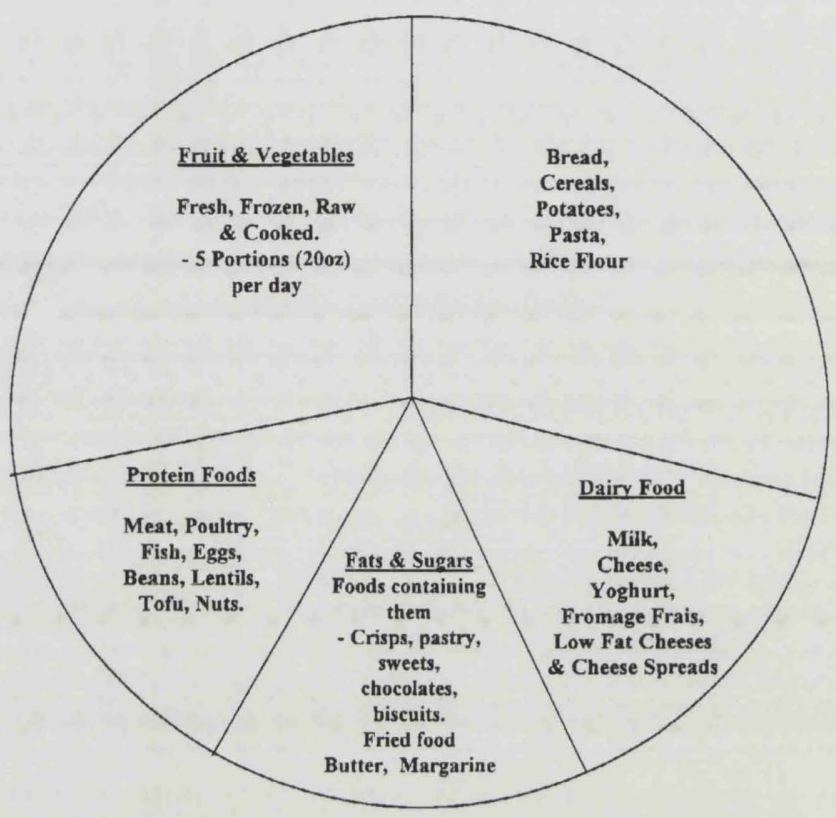

THE BALANCE OF GOOOD HEALTH (HEA 1994)

To show the relative proportions of foods to be eaten daily

meat products, spread and cooking fat, biscuits, cakes and pastries.

There is strong evidence of a direct relationship between an increased proportion of energy from saturates and increased levels of blood cholesterol, which are themselves related to an increased risk of CHD. There are different types of saturates. They do not all have the same effect on blood cholesterol levels, but they may have similar effects on other blood factors which are relevant to the risk of heart disease. More research is needed into the scientific basis and practical implications of this.

Intake of saturates has fallen from $19 \%$ of food energy in 1980 to $16 \%$ in 1992 .

Recommendation: The average contribution of saturates to dietary energy should be decreased to no more than about $10 \%$.

\section{Monounsaturates}

Rich food sources for these are rapeseed and olive oils, and sources in the diet include meat and meat products, milk and dairy products, spreads, cereal products and vegetables.

Monounsaturates do not affect levels of blood cholesterol in the same way as either saturates or polyunsaturates. When saturates are replaced in the diet by monounsaturates, both total and LDL cholesterol levels in the blood are reduced. 
Levels in the diet have remained fairly constant at about $15 \%$ of food energy.

\section{Recommendation: No specific recommendation is made.}

\section{Polyunsaturates}

There are two main families of polyunsaturates, each based on essential fatty acids. These are n-6 and n-3, and are considered separately. Rich food sources for n-6 polyunsaturates are polyunsaturated spreads, some seed oils such as sunflower, corn, and soybean. Sources in the diet include spreads, vegetables (including roast and fried), meat and meat products.

There is some evidence that higher levels are associated with reduced risk of CHD. When saturates are replaced in the diet by the main n-6 polyunsaturate, linoleic acid, levels of blood LDL cholesterol are reduced. Another effect may be to lower HDL cholesterol, although this may only be at high levels of intake. There is also some theoretical concern that oxidation of these fats at high levels in the diet could have other adverse effects.

There has been a substantial increase in n-6 polyunsaturates consumption over the last decade, and levels are now about $6 \%$ of food energy.

Recommendation: No further increase is recommended because the safety of high levels has not been demonstrated. The proportion of the population already consuming more than $10 \%$ of dietary energy as n-6 polyunsaturates should not increase.

Rich food sources for n-3 polyunsaturates include fish, especially oily types such as mackerel, pilchards and salmon, soybean and rapeseed oils. Sources in the diet include vegetables (including roast and fried), and vegetable oils, spreads, meat and meat products, cereal products, fish and fish products.

The $n-3$ polyunsaturated fatty acids have no significant effect on blood cholesterol. The 'parent', alpha-linolenic acid, however, can be changed into molecules with longer chains. These long-chain n-3 polyunsaturates reduce the tendency for the blood to clot. This is known to be beneficial in reducing the risk of a second heart attack, and it seems reasonable to suppose that it would also reduce the risk of a first one. The long-chain n-3 polyunsaturates which have this effect are found pre-formed in fish, particularly the oily kinds such as mackerel, herring, pilchard, sardine, trout and salmon.

Current average intakes of long chain n-3 polyunsaturates are about $0.1 \mathrm{~g} /$ day.

Recommendation: An increase in the population average consumption of long-chain $n-3$ polyunsaturates to about $0.2 \mathrm{~g} /$ day.

\section{Trans fatty acids}

Sources in the diet include biscuits and cakes, fat spreads, meat and meat products and dairy products.

There is increasing evidence that trans fatty acids, particularly those from margarines and cooking fat, may have undesirable effects on blood cholesterol and other relevant blood factors. This in turn increases the risk of heart disease.

Current intakes of trans fatty acids are about $2 \%$ of food energy.
Recommendation: Trans fatty acids should provide no more than about $2 \%$ of dietary energy on average, and consideration should be given to ways of decreasing the amounts present in the diet.

\section{Total fat}

Saturates are the main dietary factor as far as reducing blood cholesterol is concerned. There is increasing evidence that the total amount of fat in the diet also needs to be considered. This is because it appears to be conducive to weight gain and to an increased tendency for clots to form in the blood. In addition, there may be an association with the development of some cancers.

Current average intakes are about $40 \%$ of food energy.

Recommendation: A reduction in the average contribution of total fat to dietary energy in the population to about $35 \%$.

There are clear implications for a reduction in consumption of total fat and saturates. Monounsaturates, however, tend to be found in similar foods to saturates, and so levels of these would be reduced as well. On balance, if overall levels of dietary monounsaturates are to be maintained, it would be preferable to use oils rich in monounsaturates rather than those rich in polyunsaturates.

\section{Dietary cholesterol}

Sources in the diet include eggs, meat and meat products, butter and milk.

The amount of cholesterol in the diet has fallen markedly from $405 \mathrm{mg} /$ day in the 1970 s to $245 \mathrm{mg}$ /day in 1992 . Dietary cholesterol can significantly increase blood cholesterol. This increase is not as great as that associated with saturates, and its size will vary considerably between people.

Recommendation: The average dietary intake of cholesterol should not rise.

\section{Carbohydrates}

These include complex carbohydrates (starches and nonstarch polysaccharides or 'fibre'), and sugars. The COMA Dietary Reference Values panel ${ }^{(9)}$ considered wider aspects of health and gave reference intakes for all the different forms of carbohydrate.

Reducing total fat and saturates in the diet would result in less energy being consumed, if there were no other dietary changes. Complex carbohydrates and sugars in fruit and vegetables have an important role to play in replacing this energy. In addition, there is evidence that some forms of nonstarch polysaccharides can reduce blood cholesterol.

In the 1940 s about $53 \%$ of food energy came from carbohydrate. Since then there has been a decline to about $45 \%$ in 1992 .

Recommendation: Complex carbohydrates and sugars in fruit and vegetables should restore the energy deficit following a reduction in the dietary intake of fat. The proportion of dietary energy derived from carbohydrates should increase to about $50 \%$.

\section{Sodium}

Sodium is found mostly in common salt. Sources in the diet include bread and meat products (particularly bacon and ham), cheese and salty snacks such as crisps. In the UK diet $65-85 \%$ of salt is from manufactured foods. 
Sodium appears to be one of the causes of increased blood pressure, at least partly by influencing the rise of blood pressure with age.

Current intakes of salt are about $10 \mathrm{~g} /$ day for men, and $8 \mathrm{~g} /$ day for women.

Recommendation: Reduction in the average intake of common salt by the adult population from the current level of about $9 \mathrm{~g} /$ day to about $6 \mathrm{~g} /$ day ( $7 \mathrm{~g}$ for men, $5 \mathrm{~g}$ for women). Children would also benefit from lower intakes and proportional reductions are recommended. Food manufacturers, caterers and individuals should explore and grasp the opportunities for reducing the sodium content of food and meals.

\section{Potassium}

Sources in the diet include vegetables (particularly potatoes), fruit, meat and meat products, milk and milk products and cereal products.

There is consistent evidence showing that higher intakes of potassium are associated with low blood pressure and fewer strokes.

The current average intakes are $2.4 \mathrm{~g} /$ day for women and $3.2 \mathrm{~g} /$ day for men.

Recommendation: Increase in the average intake of dietary potassium by the adult population to about $3.5 \mathrm{~g} /$ day ( $3 \mathrm{~g}$ for women, $4 \mathrm{~g}$ for men). Children would also benefit from an increased intake, but there are currently insufficient data to quantify this.

\section{Antioxidant nutrients}

Some foods contain substances which protect against the adverse effects of excessive oxidation. There is a small amount of consistent evidence that these effects may include increased susceptibility to thickening of blood vessel walls (by oxidation of LDL cholesterol and its incorporation into the wall), and a role in the development of some cancers.

Some essential nutrients have antioxidant properties, but other non-essential substances also have a potent effect. The principal antioxidant nutrients are vitamin $\mathrm{C}$, vitamin $\mathrm{E}$ and carotenes. Vitamin $\mathrm{C}$ and carotenes are found in fruit and vegetables, particularly those which are dark green, coloured or citrus. Unsaturated oils and fats, vegetables and wholegrain cereals are the main sources of vitamin E.

Individually some nutrients have an antioxidant effect, but very large doses seem to be needed. The potential risk of purified, high-dose supplements are not known and there is some evidence to suggest that it would be unwise to assume that they are safe. They are not recommended as a widespread way of preventing CHD.

Recommendation: The evidence for a protective effect is persuasive but not yet conclusive, and the data are insufficient to make quantified recommendations for specific antioxidants. Other recommendations are increasing consumption of starchy foods, fruit and vegetables, and replacing saturated fats by unsaturated oils. These would have the effect of increased intake of antioxidant nutrients.

\section{CONSISTENCY OF ADVICE}

Research carried out in 1989 showed that most general practitioners got their nutritional knowledge from booklets, television, radio and the press ${ }^{(10)}$. Twenty-eight percent had received training from dieticians. Certainly this facility exists in the Lancaster area.

The danger of relying on the media for keeping one's knowledge up-to-date is that they may not always be reliable. Patients are more likely to consider advice to be correct (even if it isn't) when given by a doctor than when given by any other member of a multi-disciplinary team, simply because it was given by a doctor ${ }^{(10)}$. Also we cannot expect patients to act on our advice if it conflicts with what they have been told to do by the practice nurse or ward sister. We need to demonstrate that we know what we are talking about.

\section{COMPREHENSION}

Can your patients understand what you are telling them to do? Can they comprehend leaflets on food and health available in surgeries or outpatient departments? It is possible to predict the likelihood of written communication being successful by using a measure of 'reading ease' such as the FLESCH formula ${ }^{(11)}$, which analyses word and sentence length. Generally the text is less readable if the words have a large number of syllables and the sentences are particularly long: complex multi-syllabic words tend to represent abstract ideas and as such are more difficult to understand than the more concrete symbolic material.

To check on the readability of the written information which you produce, subject it to the FLESCH formula. This involves:-

1 systematically selecting several 100 -word passages

2 calculating the average number of syllables per 100 words (W),

i.e. $\quad \frac{\mathrm{n} \text { (syllables) }}{\mathrm{n} \text { (words) }} \times 100=\mathrm{W}$

3 calculating the average sentence length $(S)$,

$$
\text { i.e. } \frac{\mathrm{n} \text { (words })=\mathrm{S}}{\mathrm{n} \text { (sentences) }}
$$

4 inserting the results of these calculations into the reading ease formula, which is:

$206.84-0.85 \mathrm{~W}-1.02 \mathrm{~S}=$ reading ease score

5 comparing the final answer to those of results based on earlier standardised feedback

\begin{tabular}{|cccc|}
\hline $\begin{array}{c}\text { Reading ease } \\
\text { score }\end{array}$ & $\begin{array}{c}\text { \% who would } \\
\text { understand }\end{array}$ & $\begin{array}{c}\text { typical } \\
\text { magazine }\end{array}$ & $\begin{array}{c}\text { IQ required for } \\
\text { comprehension }\end{array}$ \\
\hline $0-30$ & 4.5 & scientific & $126+$ (superior) \\
$31-50$ & 24 & academic & $111+$ (bright) \\
$51-60$ & 40 & quality & $104+$ (high average) \\
$61-70$ & 75 & digest & $90+$ (low average) \\
$71-80$ & 80 & slick fiction & $87+$ \\
$81-90$ & 86 & pulp fiction & $84+$ (dull normal) \\
$90-100$ & 90 & comics & \\
\hline
\end{tabular}

\section{Meeting individual needs}

Even if leaflets are easy to read, they will not cause people to change their eating habits to any great extent on their own ${ }^{(12)}$. Unless advice on eating habits takes into account individual abilities, lifestyle (e.g. shift patterns), tastes in food, budget and ethnic background, it will not be taken up. For example, people on low incomes cannot afford to eat fresh fruit every day. There is much evidence to show that families in the 
lowest income brackets are most effective budgeters when it comes to food ${ }^{(13)}$. They purchase more nutrients per $£$ than anyone else, except for vitamin $\mathrm{C}$ and iron, which tend to be found in more expensive foods such as citrus fruits and red meat.

'Healthier' foods such as salad, vegetables, wholemeal bread and fish are relatively expensive. 150 calories-worth of lard costs $1.5 p$, of vegetables $£ 1$, fruit $35 p$, sausages $10 p$, whole milk $9 p$, skimmed milk $18 p$, white bread $2 p$, wholemeal bread $3 p$, and sugar $2 \mathrm{p}^{(13)}$. Budget supermarkets often do not sell a full range of 'healthier' food items (own research). Low income families tend to shop at these as it is less tempting than shopping at one of the larger chain supermarkets ${ }^{(14)}$. Family meals will usually consist of foods which are filling and cheap and which everyone will eat, so that there is little waste. Trying out new foods or dishes is risky if the children will not eat them and are then hungry ${ }^{(13)}$.

It is also important to give patients specific practical suggestions emphasising the positive, such as what you can eat, and to avoid giving vague general advice. For example "Try to eat wholemeal bread, Weetabix or porridge" is much more useful than "Eat more fibre". Some people will not know what fibre is. Others may think that it is 'bran'. When the public are asked about what kind of information they would like on diet and nutrition they usually request practical suggestions, meal plans and recipes (own research). These can then be incorporated into regular eating habits, so changing them gradually.

\section{Acknowledging that making changes in the diet is difficult and take time, persistent effort and encouragement}

The process of change is cyclical (Figure 2) and being aware of where a patient is on that cycle can mean that we assist him to move on to the next stage, which increases the chance of success ${ }^{(5)}$. So if a patient presents with eating habits which constitute a risk of CHD we need to encourage him to think about changing them by:-

\section{W weighing up the pros and cons of a healthier diet \\ $\mathbf{R}$ considering the risk \\ E establishing existing harm/damage to health \\ C discussing concerns about change}

K keeping a diary (of food eaten e.g. over a week, so that he becomes more aware of habits and tendencies) $)^{(5)}$.

This will enable the patient to prepare to change, i.e. to think about what food to buy on the next trip to the supermarket. With careful preparation and thinking time, the patient is more likely to make changes, but will need support and positive encouragement to maintain them. We all know just how tempting it is to be presented with a box of chocolates or a bottle of wine! There will always be some patients who do not wish to alter their eating habits even if they understand the risks involved. Others may not be able to make a change because of other life events such as a bereavement, loss of job or illness.

\section{Socio-economic factors which make a healthy diet less accessible to the population}

We have already seen that poverty makes healthier foods less available. In fact parents in low income families go

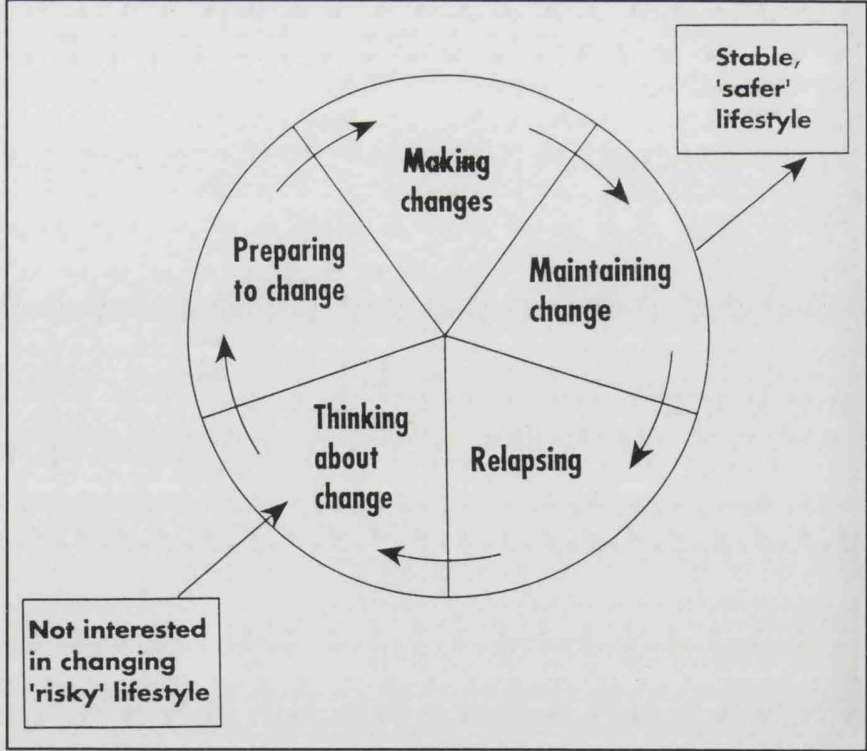

The process of change

without meals regularly ${ }^{(13)}$. They are also less likely to have the cookery skills necessary to make a nutritious low cost traditional meal such as a hotpot or stew. Many young people leave school without basic cooking skills ${ }^{(15)}$. The National Curriculum no longer includes Home Economics, which taught a comprehensive range of cooking skills. Food Technology has taken its place with a greater emphasis on designing foods and packaging for the food industry. A National 'Get Cooking' Campaign is being promoted to remedy this and several schools in Lancaster run these as extra-curricular activities.

Many low-income families do not have their own transport ${ }^{(14)}$ and many supermarkets are out of town, although the newer budget ones are nearer to residential areas. There are now fewer corner shops than before ${ }^{(14)}$ which makes it difficult for some people to shop for healthy foods. Many families surviving on benefits and/or living in Bed and Breakfast accommodation will not have access to cookery equipment. Some will not have a cooker, others will not use the oven because of the cost of the gas ${ }^{(13)}$.

All of these factors will hinder the success of any dietary advice or healthy eating campaign. Initiatives which involve empowering communities to help themselves to eat more healthily tend to be more successful ${ }^{(16)}$. These include bulk buy co-ops, community cafés and cook-and-eat groups ${ }^{(17)}$.

Perhaps health centres or primary care resources centres could provide a focus for these. Certainly, if we wish to improve the eating habits of the nation we shall need creative ideas, political will and enthusiasm, as well as a willingness to question whether one's own dietary advice is useful.

\section{REFERENCES}

1 The Health of the Nation: A Strategy for Health in England HMSO 1992

2 COMA Report: Nutritional Aspects of Cardiovascular Disease HMSO 1995

3 Doll R, Peto R The Causes of Cancer New York: Oxford University Press 1981

4 Obesity: Reversing the Increasing Problem of Obesity in England. A Report from the Nutrition and Physical Activity Task Forces Department of Health 1995 
5 Helping People Change. Health Education Authority 1994

6 Townsend P, Davidson N Inequalities in Health Penguin 1990

7 The Balance of Good Health. Health Education Authority 1994

8 Nutrition Briefing Paper: Nutritional Aspects Cardiovascular Disease Health Education Authority 1996

9 Dietary Reference Values: A Guide HMSO 1991

10 Healthy Eating - Beliefs and Attitudes National Dairy Council 1989

11 Flesch R The Art of Readable Writing London: Collier Macmillan 1949
12 Bingham S Dietary aspects of a healthy strategy for England Br Med J 1991; 303:353

13 Cole-Hamilton I, Long T Tightening Belts: A Report on the Impact of Poverty on Food London: London Food Commission 1986

14 Malseed J Bread Without Dough: Understanding Food Poverty Horton Publishing Ltd 1990

15 Get Cooking Campaign National Food Alliance London 1996

16 Prendiville V. A Community-Based Approach to Nutrition Education MSc thesis Manchester University 1990

17 Price S, Sephton J Just Desserts: Influencing Food Choice, Food Behaviour and Strategies for Change Horton Publishing Ltd 1991 